\title{
Política municipal y producción artesana: las tejerías de Daroca (siglos XV-XVII)
}

\author{
José Antonio Mateos Royo *
}

\begin{abstract}
RESUMEN
Artículo relativo al papel desempeñado por el Concejo sobre la producción de materiales de construcción en la ciudad de Daroca durante los siglos XV, XVI y xvII. Su principal objetivo era crear las condiciones más favorables para asegurar a los habitantes de la ciudad un suministro suficiente a un precio asequible. El control público atravesará sucesivas fases de crecimiento y contracción al adaptarse a la evolución de las relaciones sociales y económicas dentro de la ciudad $y$ a las circunstancias del momento.

\section{ABSTRACT}

This paper studies the role developped by the town council for the production of building materials in the Aragonese town of Daroca during the fifteenth, sixteenth and seventeenth centuries. The main goal of the town council was to create the more favourable conditions in order to get a sufficient supply ans a reasonable price for the population. This public control will pass trough different periods of growth and decrease as a result of its adaptation to the evolution of the socio-economic relations inside the town and to the specific circunstances of each period.
\end{abstract}

* Universidad de Zaragoza. 
A partir de la plena Edad Media, las villas y ciudades de Europa Occidental conocen una expansión creciente que acarrea importantes modificaciones en la organización política que representa el municipio. El crecimiento económico y demográfico, junto a su mayor peso politico, obliga a los Concejos a asumir nuevas tareas acordes con las necesidades sentidas por los habitantes de estas poblaciones.

En la Península Ibérica, esta evolución viene caracterizada por la politica poblacional desarrollada por los reinos cristianos con el fin de asegurar el control sobre las nuevas tierras conquistadas a los musulmanes. Este proceso de repoblación, al dotar de importantes libertades a las ciudades, las constituirá en unidades con una amplia autonomía política y administrativa, y con un arraigado deseo de autosuficiencia. Este anhelo se traduce en el plano económico en el desarrollo de dispositivos ligados al control público que permitan a la ciudad limitar al máximo su dependencia del exterior. Si el ejemplo clásico de esta actitud es la política de abastos, eje de actuación de los Concejos, la injerencia municipal podía orientarse a otros planos de la vida económica y ganaba en gravedad en los núcleos poblacionales más modestos, donde este proteccionismo resultaba extremo.

El presente estudio intenta profundizar en esta vía al analizar el estricto control ejercido por el Concejo de Daroca, municipio aragonés de realengo, sobre la producción de tejas y ladrillos durante los siglos $X V$, XVI y XVII. Su objetivo primordial era asegurar a la población un suministro regular de estos materiales, elementos básicos para la construcción en el reino aragonés durante las Edades Media y Moderna. La amplitud del período tratado permite reflejar los avances y repliegues de la política municipal sobre el tema, resultado tanto de la evolución general de las relaciones sociales y económicas como la del mismo Concejo como institución en sí.

\section{EL SIGLOXV}

A raíz de la documentación consultada, resulta evidente que la actividad de las tejerías de la ciudad de Daroca no constituía en su conjunto un monopolio pleno, concebido como bien de propios o fuente de ingresos municipal, dado que algunas de éstas eran de propiedad particular. La actitud del municipio se orientaba más bien a aprovechar sus prerrogativas como institución defensora del interés común para regular la apertura de nuevos tejares o someter a su control los de propiedad particular si la oca- 
sión era propicia '. En 1467, por ejemplo, el Concejo dispone que el procurador de la ciudad «tome la posessión del patio de la ollería que está cerca del molino de Lop de la Ram», situado junto a la acequia molinar. En 1489 ordenará derribar la ollería que un moro estaba construyendo al lado de la muralla que rodeaba Daroca.

Al margen de estas actuaciones puntuales, es la concesión de licencias para levantar nuevos obradores en Daroca la que permite ejemplificar con mayor claridad las directrices de la política municipal. A cambio de la entrega de un canon anual fijo en dinero - cinco, diez, quince sueldos-, el Concejo permitía a particulares el edificar una tejería u ollería en determinados terrenos que quedaban así vinculados mediante el pago del treudo a la hacienda municipal. En el acuerdo de cesión, el Concejo estipulaba ciertas condiciones de producción y mantenimiento del edificio orientadas a asegurar a la ciudad el abasto de teja y ladrillo a un precio asequible. El municipio se reservaba asimismo el derecho de arbitrio en toda disputa relativa a su funcionamiento. En 1490 , por ejemplo, nombra una comisión ${ }^{2}$ «para entrevenir en las differencias que tienen los moros olleros hermanos acerqua la ollería de la ciudat".

El conjunto de estatutos y Actas municipales permite conocer diversos ejemplos de este modo de proceder que ilustran asimismo - véase el mapa adjunto- sobre la localización en la ciudad de tejerías y ollerías ${ }^{3}$. En 1400 el municipio entrega la tejería de la Exarca, asentada en las cuatro décadas finales del Cuatrocientos en las eras bajas o fondoneras, a Blas de Valconchán, quien la detentará con sus herederos a lo largo de todo el siglo XV. Tras sucesivos acuerdos en 1449 y 1460 el Concejo cede a treudo perpetuo al moro Avdalla el ferrero una ollería localizada frente a la iglesia de San Lázaro, cerca de la rambla de Guzbert. A finales del siglo xv, entre 1493 y 1501, Lazaro Latonda explotará la tejería del Prado, que M.L Rodrigo relaciona con la situada en la dehesa de la ciudad, citada en 1411 como cedida a Juan de Briuega. De ser así, la exención del pago de todo treudo concedida al Vispe de Jargen en 1464 por su disfrute podría explicar la ausencia de toda referencia en las Actas municipales hasta fechas tan tardías.

Véase A(rchivo) M(unicipal de) D(aroca), Act(as) Mun(icipales) (AMD), 1467, 28 de enero y 1489,13 de marzo.

Véase AMD, Act Mun, 1490, 12 de marzo

3 Véase AMD, Estatutos de la ciudad (10.7.1), 1400, 8 de marzo, fol.37v-38v, 1449, 30 de dic, fol.75r-76v y Act Mun, 1460,30 de marzo y fol.98r-99v, 1464, 28 de oct, 1493, 6 de sept y $94 \mathrm{v}$, y 1502, tol..48r. Véase asimismo RoDRiGo, M.L: Poder y vida cotidiana en una ciudad bajomedieval: Daroca, 1400-1526 (tesis doctoral inédita) y ÁLVARO, M.I: "Las tejerías de Daroca y su arrendamiento municipal durante el siglo XV", Aragón en la Edad Media, (Zaragoza), VIII, (1989), págs 59-70. 
Por supuesto, el deterioro de las instalaciones o las diversas necesidades anejas a la obra de tejas y ladrillos podian condicionar cambios en la ubicación de las tejerías. En 1481, por ejemplo, el municipio decide abandonar la ollería de San Lázaro, que había sido cedida en 1449 a Avdalla el ferrero. A tal efecto, establece un nuevo acuerdo con Hiyaye el Ferrero, moro ollero, para que este construya con un subsidio municipal de 400 sueldos una nueva ollería en el camino de Sobrecarrera, en las cercanías de la acequia molinar ${ }^{4}$. Este Hiyaye -también denominado en la documentación Diayella explotará hasta ser substituido en 1489 por Hamet, ferrero moro, y éste a su vez en 1506 por Antón Moreno. La habitual presencia de mudéjares en estos acuerdos, ya destacada por otros estudios ${ }^{5}$, resulta del todo punto normal si se considera su tradicional dedicación no sólo al trabajo del barro -olleros, tejeros, cantareros, ceramistas-, sino a diversas actividades ligadas a la construcción, como carpinteros, yeseros o maestros de fábrica.

Entre las condiciones establecidas con los diversos tejeros, algunas pretendian asegurar al municipio determinadas prioridades en el destino de estos centros de producción. Por lo general, tejerías y ollerias se entregaban a treudo perpetuo, "con comiso, luismo y fadiga". Caso de querer vender la propiedad, estaba obligado a transmitir el pago del treudo y las demás condiciones pactadas con el Concejo. Debía avisar con diez días de antelación al Concejo, quien disponia de un derecho preferencial de compra por una décima parte menos de su precio justo. La indivisilidad del tejar solía ser una cláusula corriente ${ }^{6}$, como sucede en los acuerdos establecidos en 1449, 1460 y 1481 . Estos mismos compromisos fijan la imposibilidad de vender la propiedad a clérigos, caballeros, infanzones, judíos y leprosos. La mención de los tres primeros sectores sociales tenía por objeto evitar en lo posible que, al igual que sucedía con los hornos para elaborar pan ${ }^{7}$, las tejerías quedasen en poder de miembros de los estamentos privilegiados y escapasen así al control municipal.

\footnotetext{
4 Véase AMD, Act Mun, 1481, 11 de marzo, fol.88v y $93 r$ y Estatutos de la ciudad (10.7.1), 1481,28 de dic, fol. $114 r-115 r$.

5 Véase, como mejor síntesis para el reino aragonés, ÁlVARO, M.I: “El trabajo de los mudéjares y los moriscos en el reino de Navarra: estado de la cuestión", en VI Simposio Internacional de mudejarismo. Teruel, Instituto de Estudios Turolenses, 1995, págs. 7-38. Para Daroca, RodriGO, M. L.: «Los mudéjares y su fuerza de trabajo en el ámbito urbano darocense (1423-1526)" y GaRcia MARCO, F.J: «El trabajo de los mudéjares de Daroca (Zaragoza) en la segunda mitad del siglo XVm, ambas en el mismo Simposio, págs. 143-165 y 167-186.

6 Véase AMD, Estatutos de la ciudad (10.7.1), 1449, 30 de dic, fol.75r-76v y 1481, 28 de dic, fol.114r-115r y Act Mun, 1460, fol. 98r-99v.

7 Véase MATEOS, J. A: “Monopolio señorial frente a control público: hornos y panaderías en la Daroca del siglo XV", Actas del XV Congreso de Historia de la Corona de Aragón, Zaragoza, Diputación General de Aragón, 1996, tomo I, vol.V, págs. 211-224.
} 
Solia ser habitual, asimismo, la imposición por el Concejo al propietario de obligaciones específicas en la producción y suministro de tejas y ladrillos. En 1400 Blas de Valconchán sólo debía abastecer a los vecinos y habitantes cristianos de la ciudad, con exclusión de los moros y judíos. En el compromiso firmado en 1460 con Avdalla el ferrero, si bien la cláusula anterior desaparecía, éste se comprometía a obrar en la olleria hasta dos millares de rejola y otros tantos de teja. La misma cantidad aceptará elaborar Hiyaye en 1481. Como norma general, la producción de las tejerías se reservaba para los habitantes de Daroca y sólo en caso de disponer de excedentes al finalizar su arriendo se permitía al tejero su venta fuera de la ciudad.

Otro aspecto indispensable en estos acuerdos era el establecer un precio de venta fijo, a semejanza del dispuesto en los arriendos de abastos de artículos alimenticios -carne, pescado, aceite-, monopolios municipales. El tejero u ollero se comprometía a suministrar tejas y rejolas a la población al precio establecido en el contrato, que no podía variar sin licencia expresa del Concejo. De este modo, pese a no ser propietario de todas las tejerías existentes en la ciudad, el control municipal sobre las cedidas a treudo ejercía el suficiente efecto sobre el mercado como para contener las bruscas oscilaciones de precios.

Por último, resultaba necesario supervisar las medidas de las tejas y rejolas elaboradas para evitar que tejeros y olleros defraudasen mediante la elaboración de unidades de menor tamaño que las establecidas por las disposiciones municipales. El almotazaf o veedor de pesos y medidas, cargo de origen musulmán, era el encargado de supervisar la producción con objeto de asegurar su exactitud con el molde o patrón aceptado por la ciudad $^{8}$. El municipio disponía con frecuencia para facilitar su labor que toda nueva hornada de tejas y ladrillos debía extraerse del horno ante su presencia. Caso de hallar faltas en las medidas, el tejero podía verse condenado a deshacer su producción o venderla a un precio menor al estipulado, tras ser tasada por diputados nombrados al efecto.

8 Véase AMD, Estatutos de la ciudad, (10.7.1), 1481, 28 de dic., fol.114r-115r y Act Mun, 1514,7 de abril. Sobre el origen del cargo y su evolución, véase ChALMETA, P.: El señor del zoco en España. Edades Media y Moderna. Madrid, Instituto Hispano-Arabe de Cultura, 1973 y "La figura del almotacén en los fueros y su semejanza con el zabazoque hispano-musulmán", Revista de la Universidad de Madrid, (Madrid), XIX, 73, (1970), págs. 145-167. La importancia de controlar los sistemas de pesos y medidas motivó que gran número de villas o ciudades contasen con uno o varios almotazafes, como ocurre en Zaragoza. Véase FALCón, M.I.: Organización municipal de Zaragoza en el siglo xv. Zaragoza. Ayuntamiento, 1978, págs. 101-115. Para Daroca, una relación de los derechos del almotazat, en AMD, Libro del Regimiento (8.7.3), fol.56r-64v. 
A este respecto, la aceleración del crecimiento económico que se deja sentir en Daroca en la última decada del Cuatrocientos introduce novedades de consideración. En el año 1490, con el fin de favorecer la adquisición de las rejolas propias en el exterior, el municipio ordenará la adopción del molde de Zaragoza, el oficial para todo el reino aragonés: “El Consello proveio que el almotaçaf aya de referir el molde que hazen las regolas

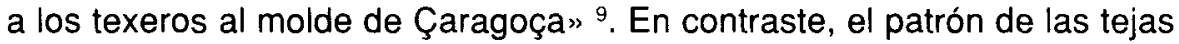
se mantendrá fiel en las centurias siguientes a los adoptados en la comarca. En concreto, el utilizado durante buena parte del siglo XVı será el molde de Báguena.

Esta variación sustancial en el molde de la rejola es la causa de que, a partir de la última década del siglo xv hasta fines del siglo XVI, el precio de la rejola será siempre inferior al de la teja, en vez de ser el mismo, como habia sido la norma hasta entonces. Al igual que ocurre en Zaragoza, los precios de la teja y rejola mantendrán en Daroca a lo largo del siglo XVI una relación de equivalencia que se puede fijar en doce sueldos a favor de la teja, como sucede en 1542-1551. Caso de dirigirse el comprador a las tejerías para recoger el producto ya terminado, obtenía una rebaja en el precio cifrada desde mediados de siglo en cinco sueldos.

Con objeto de llevar a cabo un estudio de la evolución de los precios de teja y rejola, se ha construido el cuadro 1, que recoge los datos disponibles sobre el particular para los siglos $x V$ al $x$ VII ${ }^{10}$. Las fuentes utilizadas

9 Véase AMD, Act Mun, 1490, 26 de marzo. La utilización del molde de Báguena para las tejas se menciona en AMD, Libro del Regimiento, (8.7.3), fol.95r-v y A(rchivo de) $P$ (rotocolos) $N$ (otariales de) $\mathrm{D}$ (aroca), Juan Hornos 1542, 22 de nov y Miguel Pérez, 1544, 11 de dic. Sobre la importancia de las medidas en la economía de la época preindustrial, KULA, W: Las medidas y los hombres, Madrid, siglo XXI, 1980. El molde de la rejola zaragozana en el siglo XVI ha sido fijado en unos $0,042 \mathrm{mts}$ de grueso, 0,16 de ancho y 0,336 de largo en GÓmEZ URDÁNEZ, C: «La rejola, un material de construcción en Zaragoza, en el siglo xv|», Artigrama, (Zaragoza), 1, (1984), págs. 91-95.

10 Esta relación de precios puede cotejarse en AMD, Estatutos de la ciudad (10.7.1), 1400, 8 de marzo, fol. $37 v-38 v, 1449,30$ de dic. fol. $75 r-76 v, 1481,28$ de dic. fol. 114r-115r, Libro del Regimiento (8.7.3), fol. 49v, 94v y 95r-98v y Libro de Arriendos (8.8.1) fol. 130r-131r, 152r-154r y $192 r-194 v$ y (8.8.2), fol. 4r-6r, 76v-78v y 151v-154v. También en AMD, Act Mun, 1460, fol. 98r-99v, 1473 , fol. $91 \mathrm{v}, 1476$, fol. $121 \mathrm{r}, 1479$, fol. $100 \mathrm{r}$ y $103 \mathrm{r}, 1484$, fol. $119 \mathrm{v}$ y $128 \mathrm{r}, 1485$, fol. $93 \mathrm{r}, 1497$, fol. $88 \mathrm{r}, 89 \mathrm{v}$ y $92 \mathrm{v}, 1500,20$ de marzo, 1502, 4 de nov. 1504, fol. 50r, 1553, 1 de marzo, 1560, 22 de nov., 1564, 22 de dic. y fol. 103v, 1578, 31 de enero, 1600, 15 de nov., 1604, 10 de dic. 1608, 1 de enero 1609,1611 , fol. $104 r, 1613,8$ de nov. $1616,8,20$ y 29 de mayo, 1618, 8 de mayo, 1620,25 de oct. y 130v, 1623, 17 de nov. 18 y 28 de dic. 1627, 13 de agosto, 1632, 14 de oct. 1641,13 de sept. 1643,10 de mayo, 1648, 11 de dic. 1651 , fol. $219 \mathrm{v}, 1652,19$ de enero y fol. 182v, 1653, fol. 307v, 1665, fol. 100v, 1666, 31 de julio y fol. 145r, 1668, fol. 149r, 1669, fol. 123r, 1670 , fol. $136 \mathrm{v}$ y 1671, fol. 112v. Para los años 1589, 1595, 1596, 1602, 1604, 1605, 1606, revísese las relaciones de deudas de la procuraduría general. Véase asimismo APND, Domingo Tcmás, 1490, 20 de marzo, Miguel Sancho, 1512, 28 de enero, 1542, 22 de nov. Miguel Pérez, 1544,11 de dic. y Tomás Zorrila, 1587,15 de feb. y fol. 128v. 
para elaborar el cuadro se ha ceñido en esencia a la propia documentación municipal: Actas, estatutos, libros de arriendos y de contabilidad. Como fuente complementaria, se han utilizado asimismo algunos protocolos notariales. La mayor escasez de fuentes - Actas, libros de arriendos y contabilidad-para la primera mitad del Cuatrocientos y la quiebra de la hacienda concejil en 1672 con la subsiguiente gestión de los bienes de propios por los censalistas han determinado que el mayor volumen de información localizado se concentre entre los años 1450 y 1670.

Como resultado del análisis, se percibe con nitidez la clásica inelasticidad ligada a los materiales de construcción, menos sensibles a los cambios coyunturales. Por este motivo es necesario estudiar sus alteraciones en el contexto de la larga duración con objeto de poder ponderarlas en su justa medida. Sobre el particular, la misma política municipal ya descrita se muestra muy reacia a los cambios al considerar un precio como «justo" y susceptible de ser defendido por el Concejo en caso de aumentar la demanda mientras las condiciones lo permitan. En períodos de atonía económica, el descenso de la demanda resulta ser un freno más eficaz que la actuación del Concejo, sin que ésta merezca, como se verá, dejar de ser tenida en cuenta.

En evidente contraste con Zaragoza, Valencia y otras zonas de Europa, que conocen un sensible descenso del precio de los materiales de construcción entre mediados y finales del siglo xv ${ }^{11}$, este período viene caracterizado en Daroca por la estabilidad. La demanda de estos productos se ve frenada por la nula recuperación demográfica de la ciudad, lastrada por la guerra de Cataluña y brotes epidémicos, de especial gravedad a fines del siglo xV y principios del XVI (1477, 1489, 1495, 1507, 1523-24). Esta coyuntura favorece asimismo la estabilidad o encarecimiento de los costes de producción, los cuales repercuten de forma directa en el precio de tejas y rejolas. Al localizarse los indicios de efectiva recuperación económica muy a fines del Cuatrocientos, los ligeros descensos en el valor de ambos productos que puedan acaecer en las primeras décadas del siglo siguiente perderán continuidad ante la tónica general alcista de los precios, patente en el caso de los materiales de construcción ya a mediados del siglo XVI.

\footnotetext{
1 El precio de la rejola en Zaragoza, por ejemplo, evolucionó de suponer 50 sueldos el millar en 1442 a sólo 36 en 1484. Véase FALCÓN, M.I: “La construcción en Zaragoza en el siglo xv: organización del trabajo y contratos de obras en edificios privados". Principe de Viana (Pamplona), XLVII, (1986), 2, pág. 136. Para Valencia y otras regiones europeas, AAVV: Historia económica de Europa (Universidad de Cambridge). Madrid, Revista de Derecho Privado, 1977, tomo IV, pág. 697. Pese a la evidente calidad de este estudio, debo matizar que la evolución descrita de los precios no considera los valores nominales de los diversos productos sino su conversión a gramos de plata.
} 
JOSÉ ANTONIO MATEOS ROYO

Cuadro 1. Precios de venta de la teja y rejola en Daroca (s. XV-XVII)

\begin{tabular}{|c|c|c|c|c|c|c|c|c|}
\hline Año & Teja & Rejola & Año & Teja & Rejola & Año & Teja & Rejola \\
\hline 1400 & $45 s$ & $45 s$ & 1563 & $44 s 4 d$ & $(32 s 4 d)$ & 1620 & 100 & 100 \\
\hline 1450 & $40 \mathrm{~s}$ & $40 \mathrm{~s}$ & 1564 & $44 s 4 d$ & $(32 s 4 d)$ & 1623 & 100 & 100 \\
\hline 1460 & $40 \mathrm{~s}$ & $40 \mathrm{~s}$ & 1565 & $44 s 4 d$ & $(32 s 4 d)$ & 1627 & 97 & 97 \\
\hline 1473 & $40 s$ & $(40 s)$ & 1566 & $44 s 4 d$ & $(32 s 4 d)$ & 1632 & 98 & 98 \\
\hline 1476 & $(40 \mathrm{~s})$ & $40 s$ & 1567 & $44 s 6 d$ & $(32 s 4 d)$ & 1641 & 100 & 100 \\
\hline 1479 & $40 \mathrm{~s}$ & (40s) & 1568 & $44 s 6 d$ & $(32 s 4 d)$ & 1643 & 100 & 100 \\
\hline 1482 & $40 \mathrm{~s}$ & $40 s$ & 1576 & $44 s 6 d$ & $(32 s 4 d)$ & 1646 & 100 & 100 \\
\hline 1484 & $40 \mathrm{~s}$ & $40 \mathrm{~s}$ & 1578 & $44 s 6 d$ & $(32 s 4 d)$ & 1647 & 100 & 100 \\
\hline 1485 & & $35 s$ & 1580 & $46 s$ & $34 \mathrm{~s}$ & 1648 & 100 & 100 \\
\hline 1490 & & $40 \mathrm{~s}$ & 1581 & $46 s$ & $34 s$ & 1649 & 100 & 100 \\
\hline 1497 & $40 \mathrm{~s}$ & $30 \mathrm{~s}$ & 1582 & $52 \mathrm{~s}$ & (40s) & 1650 & 100 & 100 \\
\hline 1500 & & $32 s$ & 1583 & $52 \mathrm{~s}$ & $(40 s)$ & 1651 & 100 & 100 \\
\hline 1502 & $40 \mathrm{~s}$ & & 1584 & $52 \mathrm{~s}$ & $(40 s)$ & 1652 & 100 & 100 \\
\hline 1504 & & $30 s$ & 1587 & $68 \mathrm{~s}$ & $68 s$ & 1653 & 100 & 100 \\
\hline 1512 & $37 s$ & $28 \mathrm{~s}$ & 1588 & $70 \mathrm{~s}$ & $70 \mathrm{~s}$ & 1654 & 102 & 102 \\
\hline 1542 & $48 s$ & $36 s$ & 1589 & $70 \mathrm{~s}$ & $70 \mathrm{~s}$ & 1655 & 102 & 102 \\
\hline 1543 & $48 s$ & $36 s$ & 1595 & $70 \mathrm{~s}$ & $70 \mathrm{~s}$ & 1656 & 102 & 102 \\
\hline 1544 & $48 s$ & $36 s$ & 1596 & $70 \mathrm{~s}$ & $70 \mathrm{~s}$ & 1657 & 102 & 102 \\
\hline 1548 & $46 s$ & $34 \mathrm{~s}$ & 1600 & $75 s$ & $75 s$ & 1658 & 102 & 102 \\
\hline 1549 & $46 s$ & $34 s$ & 1602 & $75 \mathrm{~s}$ & $75 s$ & 1659 & 102 & 102 \\
\hline 1550 & $46 s$ & $34 s$ & 1604 & $75 \mathrm{~s}$ & $75 s$ & 1660 & 102 & 102 \\
\hline 1551 & $46 s$ & $34 s$ & 1605 & $75 \mathrm{~s}$ & $75 s$ & 1661 & 102 & 102 \\
\hline 1553 & $50 \mathrm{~s}$ & $(38 s)$ & 1606 & $75 \mathrm{~s}$ & $75 \mathrm{~s}$ & 1662 & 102 & 102 \\
\hline 1554 & $50 \mathrm{~s}$ & $(38 s)$ & 1608 & $80 \mathrm{~s}$ & $80 \mathrm{~s}$ & 1663 & 102 & 102 \\
\hline 1555 & $50 \mathrm{~s}$ & $(38 s)$ & 1609 & $80 \mathrm{~s}$ & $80 \mathrm{~s}$ & 1665 & 106 & 106 \\
\hline 1556 & $50 \mathrm{~s}$ & (38s) & 1611 & $100 \mathrm{~s}$ & $100 \mathrm{~s}$ & 1666 & 106 & 106 \\
\hline 1557 & $50 \mathrm{~s}$ & $(38 s)$ & 1613 & $100 \mathrm{~s}$ & $100 \mathrm{~s}$ & 1667 & 106 & 106 \\
\hline 1558 & $50 \mathrm{~s}$ & (38s) & 1614 & $100 \mathrm{~s}$ & $100 \mathrm{~s}$ & 1668 & 106 & 106 \\
\hline 1559 & $50 \mathrm{~s}$ & $(38 \mathrm{~s})$ & 1615 & $100 \mathrm{~s}$ & $100 \mathrm{~s}$ & 1669 & 106 & 106 \\
\hline 1560 & $48 s$ & $(36 s)$ & 1616 & $100 \mathrm{~s}$ & $100 \mathrm{~s}$ & 1670 & 106 & 106 \\
\hline 1561 & $44 s 4 d$ & $(32 s 2 d)$ & 1617 & $100 \mathrm{~s}$ & $100 \mathrm{~s}$ & 1671 & 106 & 106 \\
\hline 1562 & $44 s 4 d$ & $(32 s 2 d)$ & 1618 & $100 \mathrm{~s}$ & $100 \mathrm{~s}$ & & & \\
\hline
\end{tabular}

$s=$ sueldos; $\quad d=$ dineros

\section{EL SIGLO XVI}

La centuria del Quinientos, si bien asume los presupuestos fijados ya en la Edad Media, aporta nuevos planteamientos sobre la gestión de ollerias y tejerías. Como norma general, el Concejo realiza durante este período una expansión de sus funciones orientada a satisfacer en mayor medida las necesidades de los habitantes de la ciudad. Estas iniciativas se 
traducirán de forma inmediata en una presencia más activa y un mayor control sobre el comercio de aquellos productos cuyo suministro se considera indispensable, como es el caso de los materiales de construcción.

De manera indudable, este interés se ve agudizado por un incremento de la demanda. El análisis de los precios de venta revela que a principios de la década de los cuarenta ya se ha consolidado un aumento significativo del precio de teja y rejola respecto al existente treinta años antes. En contraste con lo apreciado para las ciudades de Zaragoza y Valencia ${ }^{12}$, donde el ascenso de los precios es considerable a mediados de siglo, la evolución apreciada en Daroca para estas mismas fechas revela una mayor estabilidad. Esta situación se ve rota de forma muy abrupta durante la década de los ochenta al iniciar una tendencia alcista, bastante similar a la descrita por Hamilton para los materiales de construcción de Castilla la Nueva, la cual no sólo se consolidará en los años siguientes, sino que hallará continuidad en las primeras décadas del siglo XVII.

Esta evolución tan discontinua del precio de los materiales de construcción en una pequeña ciudad como Daroca parece confirmar que, junto con su mayor baratura, los pequeños centros rurales dotan a estos productos de una todavía mayor inelasticidad frente al mercado, en claro contraste con los grandes núcleos urbanos. El menor volumen de oferta y demanda, así como el mayor grado de intervención municipal, provocarían en estas poblaciones más modestas la coexistencia de amplios períodos de estabilidad con muy bruscas oscilaciones en la evolución de los precios.

De acuerdo con las líneas generales citadas, la necesidad de reestructurar el funcionamiento de las tejerías se plantea de forma directa al Concejo darocense ya a principios del siglo XVI como consecuencia de la ruina o abandono de varios centros de producción ${ }^{13}$. La tejería del Prado no era utilizada ya en el año 1502. La ultima mención conservada de la ollería de San Lázaro data de 1508. Si bien se reconoce en 1542 la dedicación en

\footnotetext{
12 El precio de la rejola en Zaragoza se mantuvo en la primera mitad del siglo xvı entre 31 y 36 sueldos para alcanzar los 40 en 1553, los 60 en la década de los sesenta y los 80 a fines de siglo. La teja conoció aumentos similares, si bien desde la década de los sesenta su precio de venta pasó a suponer 30 sueldos más que el dado a la rejola en vez de los 20 habituales en la primera mitad de la centuria. Como sucede en Daroca, el precio de la teja y rejola en los pequeños núcleos del entorno registran precios más bajos que la capital. Véase GómEZ URDÁNEZ, C.: “La rejola...", págs. 103-107. Para su comparación con los precios de materiales de construcción en Valencia, Castilla la Nueva y otras zonas de Europa, HAMILTON, E.J: El tesoro americano y la revolución de los precios en España, 1501-1650. Barcelona, Ariel, 1983, págs. 248-250 y AAVV: Historia económica..., tomo IV, pág. 697. Téngase en cuenta las observaciones expuestas en la nota anterior

13 Véase AMD, Act Mun, 1502, fol. 48r, 1508, fol. $85 r, 1542$, fol. $74 \mathrm{v}$.
} 
exclusiva como era del terreno ocupado por la tejería de Blas de Valconchán, el cese de su funcionamiento parece ser bastante anterior.

Como resultado, el municipio decide sustituir la concesión de terrenos a particulares por la propiedad efectiva de unas tejerías por el municipio. Esta mayor vinculación a la ciudad provocará que la cesión a treudo perpetuo de tejares y ollerías sea sustituida de forma paulatina por su arriendo durante un espacio de tiempo limitado, como mejor forma de adaptar sus condiciones de funcionamiento a las cambiantes circunstancias de un mercado en creciente expansión.

Así, en la contabilidad del año 1521, la tejería que había pertenecido con anterioridad a la viuda del converso Joan Cristian aparece denominada como la «tejería de la ciudat». Esta tejería, encomendada para su habilitación tanto a mudéjares ${ }^{14}$-Ayça Navarro, Rodrigo de Belvis- como a vizcaínos, pasará por un lento proceso de reestructuración que se prolonga hasta la década de los cuarenta del siglo XVI. En coincidencia con un fuerte aumento de la demanda, el municipio decide adoptar el arriendo por períodos cortos de tiempo como mejor forma de abastecer la ciudad y contener el alza de precios predecible. Por este motivo resulta tan importante fijar el valor de la teja y ladrillo en los acuerdos establecidos con los tejeros, quienes en ocasiones eran reclamados por el Concejo para trasladarse a Daroca desde sus poblaciones de residencia:

"Todo el Consejo concorde fue de parecer que los regidores concluygan con el regolero para que venga a servir a precio de cincuenta sueldos el millar de teja y ladrillo, uno con otro y como puedan ${ }^{15}$ ".

La introducción definitiva del sistema de arriendo a mediados de siglo trae consigo una ventaja adicional para el investigador: el proporcionar datos sobre la producción en las tejerias de la ciudad. A partir de la década de los cuarenta hasta principios del siglo XVII el municipio decide que el arrendador de las tejerías entregue cada año, como pago por su disfrute, un sueldo por millar de tejas o rejolas producido, cantidades que se recogen en la contabilidad de la procuraduría general, principal administración municipal ${ }^{16}$.

\footnotetext{
14 Véase AMD, Act Mun, 1521, fol. 47r, 1524, 4 de marzo, 6 de mayo, 1525, 14 de julio, 1526, 20 de abril.

15 Véase AMD, Act Mun, 1553, 1 de marzo.

is Las cifras expuestas en el siguiente cuadro pueden cotejarse en AMD, Act Mun, 1542, fol. $74 \mathrm{v}, 1545$, fol. $49 \mathrm{v}, 1548,14$ de dic. fol. $44 \mathrm{v}, 1549$, fol. $93 \mathrm{r}, 1550$, fol. 55v, 1551, fol. 70v, 1553,22 de dic. fol. $65 \mathrm{v}, 1554$, fol. $60 \mathrm{v}, 1555$, fol. $80 \mathrm{r}, 1557$, fol. $93 \mathrm{r}, 1558$, fol. $46 \mathrm{r}, 1560$, fol. $90 \mathrm{v}, 1563$, fol. $102 \mathrm{r}, 1564$, fol. $97 \mathrm{v}, 1565$, fol. $108 \mathrm{v}, 1566$, fol. $80 \mathrm{v}, 1568,24$ de dic. fol. 102r, 1569, fol. 116v, 1576, fol. $62 v, 1578,24$ de enero y fol. $115 v, 1584$, fol. 104r-v, 1584, fol. 104r-v, 1589, fol. 129r,
} 
Si se observa con atención el cuadro 2 , se puede comprobar que las tejerías bajo control de la ciudad han experimentado con respecto al siglo $X V$ un aumento indiscutible en su capacidad para abastecer a la población. Si los mudéjares Avdalla o Hamet, a quienes se encomienda la ollería de San Lázaro entre 1460 y 1490, debían comprometerse a elaborar 2.000 tejas y otras tantas rejolas cada año, la producción anual de las tejerías de la ciudad durante la segunda mitad del siglo xvi ronda, $y$, con frecuencia, supera la centena de millar de tejas y rejolas.

Cuadro 2. Producción de tejas y rejolas en la tejerías de la ciudad (1542-1613)

-en millares-

\begin{tabular}{lccccc}
\hline Año & Producción & Año & Producción & Año & Producción \\
\hline 1542 & 78 & 1564 & 152 & 1595 & 130 \\
1545 & 120 & 1565 & 120 & 1596 & 90 \\
1548 & 130 & 1566 & 150 & 1597 & 140 \\
1549 & 130 & 1568 & 135 & 1600 & 153 \\
1550 & 142 & 1569 & 140 & 1602 & 140 \\
1551 & 110 & 1576 & 95 & 1604 & 139 \\
1553 & 150 & 1577 & 66 & 1605 & 140 \\
1554 & 100 & 1578 & 112 & 1606 & 150 \\
1555 & 100 & 1584 & 112 & 1608 & 100 \\
1557 & 75 & 1586 & 190 & 1609 & 96 \\
1558 & 100 & 1589 & 100 & 1611 & 130 \\
1560 & 100 & 1591 & 160 & 1613 & 120 \\
1563 & 153 & 1593 & 190 & & \\
\hline
\end{tabular}

La mayor cantidad de material requerido se acompañaba de un renovado interés por la regularidad en el abasto. Así, los arriendos de las tejerías municipales establecidos en esta centuria fijaban la obligación de proveer a la ciudad de tejas y ladrillos desde mediados de marzo hasta noviembre. Ya a mediados de siglo, en coincidencia con la expansión de edificaciones públicas y privadas, se obligaba al arrendador a tener dispuestas para cocer tras los meses de enero, febrero y marzo entre 18.000 y 20.000 rejolas con objeto de poder atender de forma inmediata a las necesidades de los particulares.

\footnotetext{
1591 , fol. 89 r, 1593 , sin fol. 1595, fol. $80 v, 1596,22$ de nov. fol. 87r, 1597, 12 de dic. fol. 55r, 1600 , fol. $106 \mathrm{r}, 1602$, fol. $47 \mathrm{r}, 1604$, fol. $68 \mathrm{v}, 1605$, fol. $77 \mathrm{r}, 1606$, fol. $79 \mathrm{r}, 1608$, fol. $50 \mathrm{r}, 1609$, fol. $56 \mathrm{r}$, 1611, fol. 104r y 1613, fol. 83r y APND. Tomás Zorrilla, 1587, (1479), 1 de feb. Los precios del siglo xV se basan en las listas - corregidas y ampliadas- expuestas por RoDRigo, M. L: Poder y vida cotidiana... El dato de 1580-81 en Álvaro, M.I: "Las tejerías de Daroca...", pág. 66.
} 
Para responder a este incremento de la demanda, era condición indispensable el construir y habilitar hornos dotados de una mayor capacidad, cometido conferido con frecuencia a los mismos tejeros ${ }^{17}$. En 1555 el municipio establece para el nuevo arrendador de las tejerías la obligación de construir dos hornos nuevos, con capacidad para 12.000 y 8.000 rajolas, de forma respectiva. En el siguiente arrendamiento, suscrito para el período 1561-1564, se exige al vizcaíno Pedro de Aranzadi el levantar un horno «de doze mil rajolas de cabida o más", condición aplicada en siguientes arriendos de los obradores. En 1580, este mismo tejero vuelve a comprometerse a construir otro más pequeño, con objeto de garantizar la existencia de dos hornos con la capacidad citada de 12.000 y 8.000 rajolas. El Concejo debe colaborar a veces en los gastos: en 1589, por ejemplo, destinará 1.100 sueldos a reparar un horno en las tejerías altas.

En los contratos de arriendo se detalla con especial cuidado el uso de los tres principales materiales empleados para fabricar tejas y rejolas: leña, tierra y el agua ${ }^{18}$. El arrendador contaba para procurarse madera con los mismos derechos comunales que el resto de los vecinos de Daroca. Debía extraer la tierra de aquella zona señalada por los regidores de la ciudad al efecto y ahondar todo aquello que éstos estimasen oportuno, motivo de queja en ocasiones por parte del tejero al considerar la calidad o cantidad de la misma insuficiente. Con objeto de garantizar el buen mantenimiento de las balsas utilizadas para mezclar el barro, el tejero se comprometía a limpiar con regularidad el brazal construido por el Concejo «para espidir el angua de los bolsones por la cantarilla que hizo".

Como resultado de las modificaciones efectuadas en la rejola a fines del siglo XV, el control sobre la producción de las tejerías de la ciudad durante buena parte del Quinientos se efectuaba con tres patrones diferentes ${ }^{19}$. Para la teja, el moide de Báguena. Para la rejola utilizada para edificar, el molde del almotazaf, adaptado como se ha dicho según el patrón de Zaragoza. El molde antiguo se utilizaba para elaborar la rejola "de enrejolar» o ladrillo abizcochado destinado a cubrir los suelos y los "pisones", con-

\footnotetext{
17 Véase AMD, Libro del Regimiento, (8.7.3), fol.98r-v.

18 Ibidem, fol. $96 \mathrm{r}$. Sobre la proximidad de las tejerias a cursos de agua y tierras arcillosas, Alvaro, M.I. Cerámica aragonesa decorada. Zaragoza, Librería General, 1976, tomo I, págs. 39-40 y "L.ocalización y especialidades de algunos obradores cerámicos situados en focos urbanos aragoneses", IV Jornadas sobre el estado actual de los Estudios sobre Aragón. Zaragoza, Universidad, 1982, pág. 561.

19 Véase AMD, Libro del Regimiento, (8.7.3), fol. 95v-96r. Sobre las diversas clases de ladriIlo, Borrás, G.: Arte mudéjar aragonés. Zaragoza, Guara, 1978, tomo I, págs. 140-142 y Álvaro, M.I.: "Las tejerías de Daroca...", págs. 69-70.
} 
siderados por G. Borrás como una variedad de ladrillo aplantillado. Esta diversificación de la rejola aplicada a su uso específico se prolongará en el siglo XVII con la producción del denominado "ladrillete liso".

A partir de mediados de siglo, con el fin de favorecer la puesta en funcionamiento de los tejares por los sucesivos arrendadores, el Concejo estipulaba en el acuerdo el préstamo con un interés del $5 \%$ de una cantidad de dinero destinada al efecto, denominada vistreta. Esta suma, cifrada en principio en 1.000 sueldos, pasará a suponer 2.000 a fines del siglo XVI y durante todo el XVII. Dentro de la vistreta se solían incluir los excedentes de teja y ladrillo dejados por el anterior tejero, tras ser tasados por expertos, lo que permitía acelerar el proceso de transmisión ${ }^{20}$. Estos excedentes, evaluados en dinero, se incluían a veces entre los ingresos, gastos y relaciones de deudas de la misma contabilidad municipal, como sucede entre 1587 y 1621 ó entre 1665 y 1671 . Fuentes de considerable importancia para la localización de precios, su trabajo requiere un conocimiento previo del sistema de equivalencias en los precios de tejas y rejolas, así como del existente para un mismo producto entre la venta a domicilio o el propio transporte por el comprador del material ya elaborado.

Pese a todas estas medidas, el aumento de la demanda en las décadas de los setenta y ochenta no podía ser cubierto por un solo tejar, por lo que se introduce la figura de un segundo arrendador dedicado a abastecer a Daroca ${ }^{21}$, puesto confiado de forma ocasional al tejero de la vecina localidad de Luco. Por estas fechas -1576, 1578- se constata la existencia en la ciudad de un segundo tejar propiedad del municipio. A partir de la década de los noventa hasta su venta en 1616, ambas instalaciones serán arrendadas a una misma persona.

Estos obradores son citados en la documentación municipal de fines del XVI y principios del XVII como las tejerías altas y bajas, denominaciones cuyo uso perdurará en Daroca hasta nuestros días ${ }^{22}$, a pesar de diversos cambios de ubicación de los tejares. Ambos topónimos se localizan - véase Fig. 1- en la zona situada a ambos lados del antiguo camino real que conducía a la Puerta Alta, una de las principales entradas de la ciudad. La nueva localización de las tejerías fue posible a raíz

\footnotetext{
Véase, como ejemplos, AMD, Act. Mun, 1595, 8 de dic. y 1604, 10 de dic.

Véase AMD, Act. Mun, 1576, fol. 62v. 1578, fol. 115v, 1584, fol. 104r-v, 1589, fol. 129r y 1616, 12 de marzo.

22 En concreto, las tejerías altas se ubican en el terreno situado al Este de la ermita de Santa Quiteria, junto a la rambla de la fuente del Barreno, donde se junta con el camino de Villarroya. El topónimo tejerías bajas se aplica al espacio comprendido entre la rambla de la Mina Vieja y la rambla de la Pesquera, a mano derecha de la carretera Zaragoza-Teruel.
} 


\section{LA CIUDAD DE DAROCA EN EL SIGLO XVI}
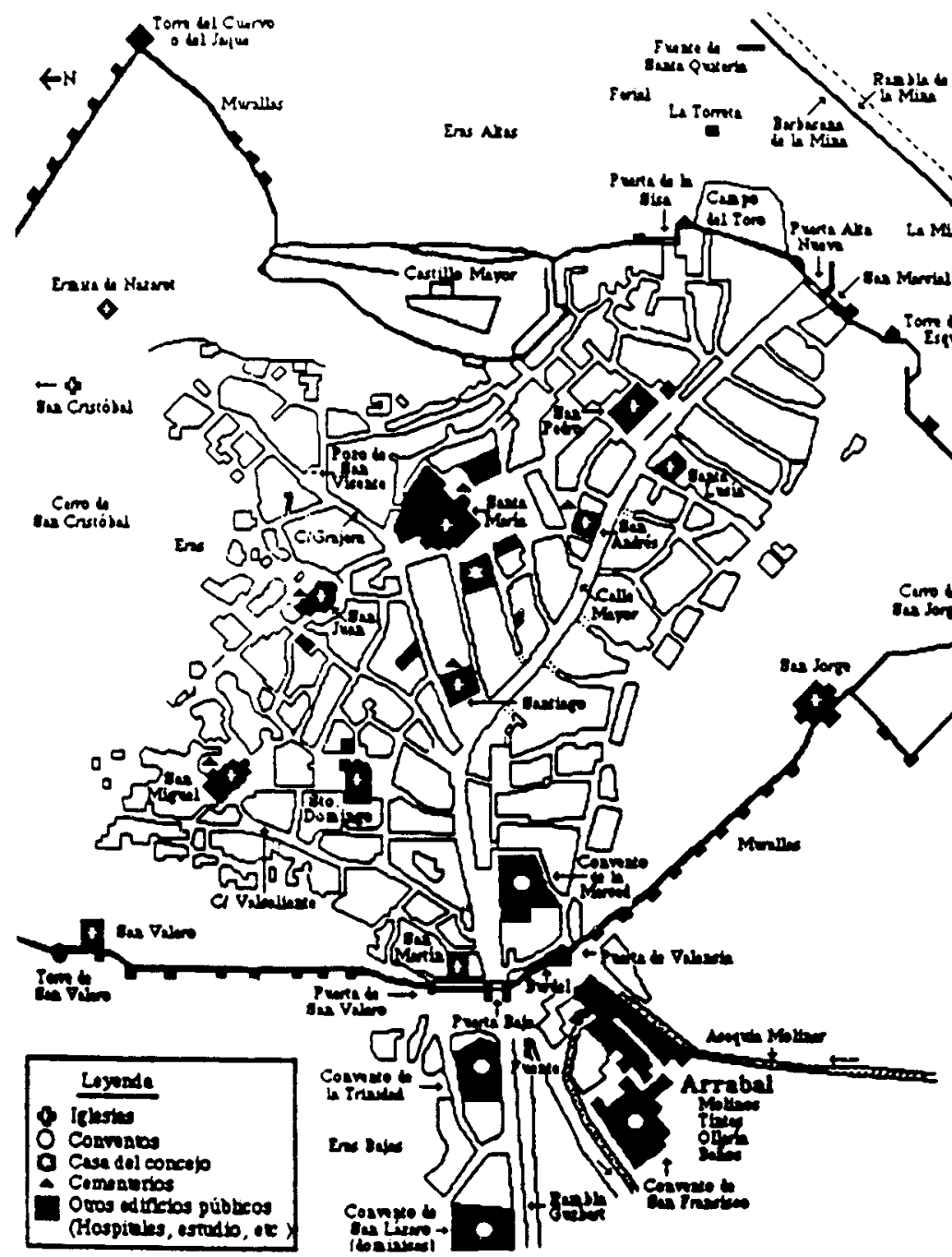

Ins Ares

(6) is la Mis
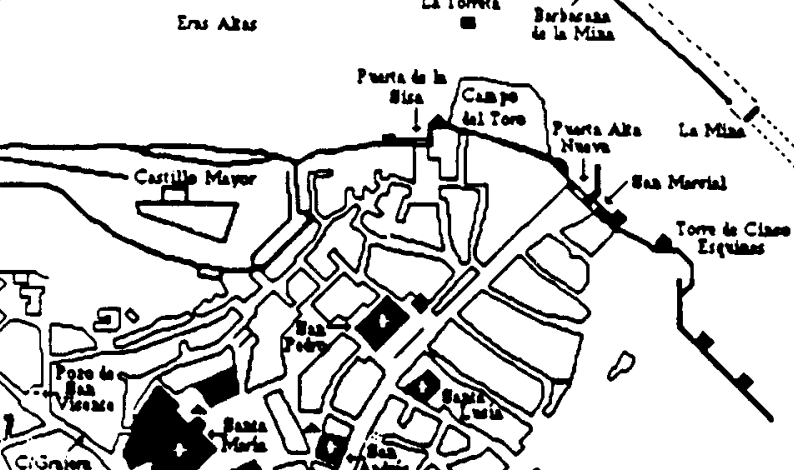

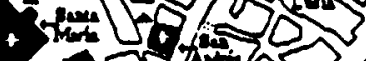

\section{$\otimes$}

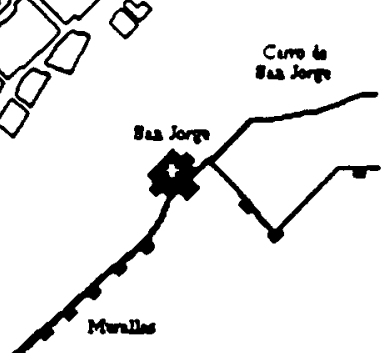

Figura 1. Según Corral, J.L.: “Catástrofes naturales y transformaciones urbanas en la ciudad de Daroca en los siglos XV y XVI», Aragón en la Edad Media,

(Zaragoza), X-XI, (1993) pág. 195. 
de los intentos municipales a mediados del siglo XVI por dotar a Daroca de una red de abasto de agua estable. Como complemento a las obras de ingeniería ligadas a la Mina, túnel destinado a preservar a la ciudad de las inundaciones, la Junta creada al efecto construyó una red de canalizaciones ${ }^{23}$ subterráneas que, tras partir de la fuente de las Chillandres, atravesaba este lugar para surtir de agua a Daroca.

El aumento de la demanda acaecido a fines de siglo trae consigo un nueva modificación de los moldes utilizados para elaborar teja y rejola, que se puede fechar hacia 1585, en coincidencia con el inicio de la reforma de la iglesia Colegial y una espectacular alza de precios. En el Libro del Regimiento de la ciudad ${ }^{24}$ correcciones efectuadas en los márgenes de los estatutos, elaborados a mediados de siglo, confirman el hecho. El molde de Báguena deja de constituir el marco de la ciudad para producir tejas. Por el contrario, como había sucedido durante buena parte del siglo XV, los moldes para elaborar teja y rejola tienden a identificarse. Por este motivo, los precios de una y otra se igualan en 68 sueldos en el segundo quinquenio de la década de los ochenta. Esta relación de equivalencia se mantendrá - véase el cuadro 1- a lo largo de todo el siglo XVII.

Respecto a las personas que detentan las tejerías de la ciudad, las noticias recogidas confirman lo expuesto por otros estudios ${ }^{25}$. Tras su conversión forzada en 1526, los moriscos siguieron ejerciendo un papel destacado en el trabajo del barro. Así, entre los arrendadores de las tejerias de la ciudad durante la segunda mitad del XVI se cuentan diversos cristianos nuevos: un miembro de la familia Salazar en 1551, Pedro Mediana a lo largo del período 1553-1558 y Pedro Navarro entre 1565 y1569.

Junto a los moriscos, destaca asimismo entre los arrendadores la acostumbrada presencia de personas procedentes del País Vasco, que parece ganar en importancia en la segunda mitad de siglo, en especial en sus dos décadas finales. Entre 1545 y 1550 Juan de Arançain o de Arançadi se halla al frente de las tejerías de la ciudad. Entre 1561 y 1564 será Pedro Aranzadi, alias Aguirre, quien se hará cargo de las mismas. La década de los setenta y ochenta conoce la actividad de Juan de Arançadi (1581-1582), Juan de Urrutia $(1576,1578,1584,1587)$ y Juan Entí, a quien son encomendados los obradores en los años finales de la centuria $(1589,1591,1595-97)$.

23 Véase MATEOS, J.A: "En torno al suministro de agua en las ciudades aragonesas: la Junta del Aguaducho de Daroca (1555-1675), Espacio, Tiempo y Forma, (Madrid), IV, 7, (1994), vol. II, págs. 29-54.

24 Véase AMD, Libro del Regimiento, (8.7.3), fol.95r.

25 Sobre el tema, véase las referencias expuestas en la nota 16. 


\section{EL SIGLO XVII}

En contraste con la centuria del Quinientos, el siglo XVII asiste a un repliegue progresivo del municipio en la esfera de actuación. Ante el debilitamiento progresivo de su hacienda, el Concejo se ve obligado a ceder parcelas de intervención a particulares en ciertos abastos, con anterioridad bajo el ferreo control municipal. El ascenso de la presión fiscal sobre los vecinos de la ciudad, relacionada de forma directa con el pago de servicios y contribuciones de guerra a la monarquía ${ }^{26}$, favorece que los circuitos comerciales se contraigan, los intercambios se alejen de la plaza pública y proliferen la reventa y la especulación. El creciente desorden monetario contribuye al encarecimiento de los artículos de consumo, en especial durante las décadas centrales del siglo. Como se pone de relieve en los productos artesanales ${ }^{27}$, el Concejo asiste impotente a una pérdida de presencia en el mercado que no puede verse detenida por la multitud de disposiciones municipales, cuya reiteración evidencia su incumplimiento.

En este contexto, el normal desarrollo de las producciones ligadas al trabajo del barro se ve quebrado de forma brusca a principios del Seiscientos. En 1610 el rey Felipe III dictamina la expulsión de los moriscos de la Corona de Aragón, tal y como se había llevado a cabo el año anterior en Castilla ${ }^{28}$. Este proceder supuso a nivel global, sobre todo en los reinos de Aragón y Valencia, dotados con una importante población morisca, una sangría humana y económica muy difícil de superar. En el plano local, la especialización de los moriscos en determinadas actividades artesanales trajo consigo abundantes problemas para los Concejos, que debieron apresurarse a buscar nuevos pobladores que asumiesen las labores ejercidas con anterioridad por los moriscos.

Daroca, al igual que otras tantas poblaciones aragonesas, vio resentida de gravedad su producción cerámica autóctona a partir de 1610. La cantarería ${ }^{29}$ existente en la ciudad, vendida por sus propietarios moriscos a Juan Esteban

26 Véase MATEOS, J.A.: “Poderes municipales y fiscalidad regia: el pago por la ciudad de Daroca del servicio de 1626", en ForTEA, J.I. y CRemAdeS, C.M. (eds), Política y Hacienda en el Antiguo Régimen. Murcia, Universidad, 1992, págs. 405-417 y «Poderes municipales y contribuciones de guerra: el Concejo de Daroca y la secesión de Cataluña (1640-1652)", en AAVV: Monarquía, Imperio y pueblos en la España moderna. Alicante, Universidad (en prensa).

27 Véase MATEOS, J. A.: «Política municipal y proteccionismo corporativo: conicejo y gremios en la Daroca del siglo xvil”, Jerónimo Zurita (Zaragoza), 69-70, (1994), págs. 129-146.

28 Sobre la población morisca de los reinos peninsulares, véase como mejores síntesis, REGLA, J.: Estudios sobre los moriscos. Barcelona, Ariel, 1974 y Dominguez ORTIZ, A. y VINCENT, B.: Historia de los moriscos. Madrid, Alianza, 1989.

${ }_{29}$ Véase APND, Jaime Marco, 1612, 27 de marzo, y AMD, Act. Mun, 1611, 20 de mayo, 1613, 7 de junio, 29 de nov. 1618, 26 de enero, 23 de feb. y 1623, 21 de abril. 
de Bolluz, comisario de su Majestad, debe ser recuperada por el Concejo en 1612 para asegurar su funcionamiento y se convierte en bien de propios municipal. Pese a que entre los recién avecindados en Daroca tras la expulsión de los moriscos se cuentan dos cantareros, las dificultades iniciales para contar con un abasto de cerámica regular y suficiente son evidentes. En 1618 se reconoce la conveniencia de reparar el horno. En 1623, el regidor Valero Rubio indicaba que «la cantarería de dicha ciudad, por no trabajar en ella, y la olla del horno están muy divididas, maltratadas", por lo que recomendaba su entrega a treudo.

A diferencia de las tejeros, la obra de cantarería desarrollada en el siglo XVII en Daroca no se halla vinculada a ningún grupo social definido y los arrendadores se cuentan entre los vecinos de la ciudad. Con todo, la baja calidad de la obra parece ser la tónica general, como demuestra la frecuente denuncia por el arrendador de la violación de su monopolio de venta en Daroca ${ }^{30}$. Así en 1654 el Concejo acepta la petición de Francisco Griñán y manda «que nadie comprase de la obra que se trae de fuera para revender sino que los vecinos se proveiessen". En 1690 el cantarero "suplica a la ciudad impida se vendan en ésta cantaros y botijas". En 1665 , por el contrario, es el municipio quien debe ordenar a la ollera y a Felipe la Plancha que cesen de comprar cerámica del exterior y se dediquen a vender la que ellos mismos elaboran.

Con respecto a las tejerías, la salida de los moriscos de Daroca coincide con el desplazamiento de la ubicación de los tejares bajo control municipal. En marzo de 1616 el Concejo decide vender las tejerías altas y bajas y establecer los nuevos tejares junto a la Mina, dado que se cuenta con "muy buena tierra, que podrá haber para muchos años" ${ }^{31}$. Procede asimismo a la compra de una era "para enjugar la teja y ladrillo" y de otro terreno para el horno, que el tejero se compromete a edificar y mantener durante ocho años si el Concejo le concede 2.000 sueldos al efecto.

A un nivel más profundo, la marcha de tejeros, olleros y cantareros moriscos desequilibra la política municipal relativa a la producción cerámica. Si durante buena parte del siglo xVI el aumento de la demanda había beneficiado la contención de los precios por el Concejo, el hueco dejado por los nuevos convertidos eleva de manera inmediata el coste de la teja y rejola, en ascenso ya desde fines del Quinientos. En 1611 el precio de ambos materiales - véase el cuadro 1-se eleva a 100 sueldos, un $20 \%$ más que el existente tan sólo dos años antes, cifrado en 80 sueldos. Pese

30 Véase AMD, Act Mun, 1654, 10 de julio, 1665, 22 de mayo, 1690, 15 de sept.

31 Véase AMD, Act Mun, 1616, 12 de marzo. 
a que en los arriendos establecidos entre 1611 y 1617 el Concejo pretende paliar este aumento al rebajar el precio de venta en veinte sueldos si el transporte corre a cuenta del comprador ${ }^{32}$, ya en 1618 esta relación se establece en diez sueldos, norma observada de forma estricta en adelante. Con descensos de escasa entidad -1627, 1632-, los precios de la teja y rejola se mantendrán en torno a los cien sueldos hasta principios de la década de los setenta.

La carencia de artesanos expertos en el trabajo del barro a raíz de la expulsión de los moriscos genera una mayor necesidad de mantener los centros de producción vinculados al Concejo. Como resultado, a lo largo de la centuria del Seiscientos los gastos de mantener las tejerías ${ }^{33}$-procurar tierra, reparar los hornos-, con anterioridad confiados a sus arrendadores, se convertirán en un lastre constante para la ya de por sí bastante debilitada hacienda municipal. La asunción de estos costes durante un periodo de especial crisis constituye un excelente ejemplo de la importancia otorgada por parte del Concejo al suministro de tejas y ladrillos efectuado por las tejerías de la ciudad.

Ahora bien, la disponibilidad del municipio para hacer frente a estas reparaciones no será siempre igual. En ocasiones, el Concejo debe conferir estos gastos al tejero, previa concesión de un canon más bajo en el arriendo, el cual volvía a subir cuando el municipio invertía dinero en las tejerias ${ }^{34}$. Este hecho explica que el coste del arriendo pase de suponer 800 sueldos anuales en 1618-1636 a nada en absoluto en 1637-1641 para mantenerse en 400 sueldos en $1642-45$ y 300 en 1646-55. Las reparaciones efectuadas en 1656 permiten al Concejo elevar el precio del arriendo hasta 1.300 sueldos en 1656-1658, que se verá obligado a descender a 800 en 1659-1661 y a 500 en 1662-1663, conforme el estado de las tejerías empeora.

Otra consecuencia asociada a la expulsión de los moriscos es el predominio indiscutido de personas oriundas de Vizcaya y Guipúzcoa en el arriendo de las tejerias municipales durante la primera mitad del Seiscientos ${ }^{35}$. A de oct.

32 Véase AMD, Libro del Regimiento (8.7.3), fol. $94 v$ y Act. Mun, 1618,8 de mayo y 1620, 25

${ }_{33}$ Véase AMD, 1602, 12 de abril, 15 de mayo, 27 de sept. 1621, 15 de marzo, 1623, 13 de enero, 20 y 30 de marzo, 7 de abril, 1627, 19 de marzo, 1630, 13 de dic, 1631, 14 de marzo, 9 de mayo, 1651, 3 de marzo, 27 de oct. 10 de nov. 1674, 9 de marzo, 1691,19 de enero, 6 y 13 de abril, 1695,15 de julio.

${ }_{34}$ Véase sobre el particular las referencias expuestas en la nota siguiente.

35 Véase AMD, Act Mun, 1600, fol.106r, 1602, fol. 47r, 1604, fol. 68v, 1605, fol. 77r, 1606, fol. 79r, 1608, fol. 50r, 1609, fol. 56r, 1611, fol. 104r, 1613, fol. 83r, 1618, fol .77v, 1620, fol. 112r, 1621 , fol. $66 \mathrm{r}, 1623$, fol. $134 \mathrm{r}, 1627$, fol. $87 \mathrm{v}, 1628$, fol. $112 \mathrm{v}, 1620$. fol. $102 \mathrm{r}, 1631$, fol. $89 \mathrm{r}, 1632$, fol. $178 \mathrm{r}, 1633$, fol. $171 \mathrm{r}, 1634$, fol. $155 \mathrm{v}, 1635$, fol. $203 \mathrm{v}, 1636$, fol. $145 \mathrm{v}, 1637$, fol. $98 \mathrm{r}, 1638$, fol. 
Juan de La Ronda o Larrondo y a Martín de Goya, tejeros de la ciudad en 1600-1606 y 1608-1613, les suceden Pedro de Mendía o Mendiguro en 1613-1617 y Juan de Mendiguro, quien detenta las tejerías sin interrupción entre 1620 y 1648 . Juan Estarri y Cholvi Chavarria le sustituirán en 16491651. El desempeño por vascos de actividades profesionales complementarias ligadas a la construcción, como el establecimiento de hornos para hacer cal, y las frecuentes dificultades del municipio para arrendar las tejerías contribuyen a explicar su predominio. Sólo en el tercer cuarto de siglo, este vínculo parece aflojarse y vecinos carentes de este origen geográfico -Pedro Luzón, Jusepe Quilez- acceden al disfrute de las tejerías de la ciudad.

La conservación de los contratos de arriendo de los tejares para el período 1646-1663 permite conocer detalles adicionales sobre las características de la producción a mediados del Seiscientos ${ }^{36}$. En todos los acuerdos se somete la elaboración de teja y ladrillo a los moldes de la ciudad. Las "tejas maestras", que vertebran la disposición de las demás en los tejados, deben cocerse según el marco de Calatayud. Este patrón debía ser mayor que el de Daroca, dado que el precio de la teja maestra se fija en 116 sueldos y 8 dineros el millar, mientras el de la darocense alcanza sólo los 102 sueldos. El tejero debía proveer asimismo a los vecinos de "ladrillete liso", de nuevo conforme al marco de la ciudad y a precios muy similares a los de la rejola: 100 sueldos el millar a domicilio y 90 en el tejar. En todos los arriendos se insiste sobre la necesidad de emplear tierra cernida para cocer las tejas, en especial cuando se trata de las maestras.

A semejanza de lo ocurrido con la cantarería, las Actas municipales aportan abundantes noticias sobre las deficiencias de la producción tejera a lo largo del siglo XVII, que parecen agravarse en la segunda mitad de siglo. Junto a deficiencias de calidad ${ }^{37}$, un problema muy común es la elaboración de teja y ladrillo con moldes más cortos que los establecidos por los estatutos municipales ${ }^{38}$. Regidores y almotazaf se ven obligados a

$99 r, 1639$, fol. $167 v, 1640$, fol. $157 r, 1642$, fol. $248 r, 1643$, fol. $167 r, 1644$, fol. $191 r, 1645$, sin fol. 1646, fol. $161 \mathrm{r}, 1647$, sin fol., 1648 , fol. $157 \mathrm{r}, 1650$, fol. $137 \mathrm{v}, 1651$, fol. $202 \mathrm{v}, 1652$, fol. $192 \mathrm{r}$, 1653, fol. $287 \mathrm{v}, 1654$, fol. $171 \mathrm{v}, 1655$, fol. $150 \mathrm{v}, 1656$, fol. $155 \mathrm{r}, 1658$, fol. $140 \mathrm{v}, 1659$, fol. $103 \mathrm{v}$, 1660, fol. $145 \mathrm{v}, 1661$, fol. $128 \mathrm{v}, 1662$, fol. $100 \mathrm{v}, 1663$, fol. $101 \mathrm{r}, 1664$, fol. $105 \mathrm{r}, 1665$, fol. $100 \mathrm{v}$, 1666, fol. $145 \mathrm{r}, 1668$, fol. $149 \mathrm{r}, 1669$, fol. $123 \mathrm{r}, 1670$, fol. $136 \mathrm{v}, 1671$, fol. $112 \mathrm{v}, 1672$, fol. $120 \mathrm{v}$.

36 Véase AMD, Libros de Arriendos (8.8.1), fol.130r-131r, 152r-154r y 192r-194v y (8.8.2), fol. $4 r-6 r, 76 v-78 v$ y $151 v-154 v$.

37 Véase AMD, Act Mun, 1654, 6 de marzo, 1663, 24 de agosto.

38 Véase AMD, Act Mun, 1609, 7 de agosto, 1650, 18 de feb. 1651, 11 de nov. 1652, 12 de enero, 1675, 21 de mayo, 1677, 21 de mayo, 1679, 11 de agosto, 1691, 19 de enero, 1695, 21 de agosto. 
realizar continuos controles y, en su caso, efectuar tasaciones a la baja de la obra defectuosa. Este desorden se incrementará al pretender el municipio en 1691 adoptar el molde de Calatayud para elaborar tejas y rejolas. En 1695, no obstante, se volverá a recurrir al molde antiguo para elaborar ladrillos al crecer las quejas de los vecinos por la reducción efectuada y al considerarse que de este modo la producción era de igual tamaño que la de Zaragoza, la capital del reino.

\section{CONCLUSIONES}

Como conclusiones, debo destacar la importancia otorgada a los obradores vinculados al trabajo del barro en el seno de las pequeñas ciudades y aldeas, mucho más vinculadas al mundo rural, durante la época preindustrial. Pese a su carácter autárquico, su función en el normal desarrollo de la vida cotidiana y el coste del transporte a larga distancia convertían a estos centros de producción en núcleos vitales para la subsistencia de la Comunidad.

El Concejo, como principal institución garante del interés común, intervendrá en el funcionamiento de tejerías, ollerías y cantarerías, con especial intensidad en las primeras, dados sus vínculos con el proceso de construcción. La actividad pública tenía como principal objetivo crear las condiciones más favorables para asegurar a los habitantes un suministro suficiente a un precio asequible. El mayor grado de intervencionismo municipal propio de las pequeñas poblaciones se evidencia en el caso de Daroca, al asumir una amplia variedad de aspectos relacionados con la producción de teja y rejola que abarcan desde la procura de materiales hasta el elaborado final.

Ahora bien, la influencia del Concejo sobre las tejerías no se mantiene estática a lo largo de los siglos, sino que atraviesa diversas fases de acuerdo con la evolución del municipio y de las relaciones sociales y económicas en el seno de la Comunidad. Así, en Daroca la cesión a treudo típica del Cuatrocientos se ve sustituida en el siglo siguiente por el arriendo en aras de lograr un mejor abasto y un mayor control municipal. En el Seiscientos la recesión económica y el exilio morisco propician a su vez acuerdos más estáticos y una menor presencia en el mercado del Concejo, quien debe aceptar la evidencia del retroceso en calidad y condiciones del suministro. En definitiva, este proceso de sucesiva expansión y contracción del control público sobre las producciones de teja y rejola ratifica el papel regulador del municipio, su importancia dentro de la Comunidad y su necesaria adaptación a las circunstancias del momento. 